\title{
Assessment of regional transport accessibility indices for inland water transport services
}

\author{
Tatiana Pantina ${ }^{1, *}$ and Svetlana Borodulina ${ }^{1}$ \\ ${ }^{1}$ Admiral Makarov State University of Maritime and Inland Shipping, 5/7, Dvinskaya str, Saint- \\ Petersburg, Russia, 198035
}

\begin{abstract}
The paper is devoted to the study of the features of the formation and calculation of indicators of transport accessibility of regions from the point of view of the provision of inland water transport services in the passenger transport segment. The key area of the research is to determine the parameters of accessibility of river transportations in the context of the spatial development of the country and the course taken on the social economy. The research is based on scientific works in the field of economics, management, economic geography, and regional economics. The paper analyzes domestic and foreign publications on the subject of the study. Based on the systematization of the research results, the authors propose a description of the transport accessibility indicator, and determine regional accessibility indices for river passenger transportation. The result of the research is the development of theoretical positions in the field of economics and management of inland water transport in the context of spatial development. The obtained results and conclusions of the study can be the basis for the formation of a planning methodology of passenger transportation by inland water transport, and also to control the process of investing in transport infrastructure in the regions, the formation of target strategic parameters of transport provision in the context of spatial development of the country.
\end{abstract}

\section{Introduction}

The spatial development of the territories of the Russian Federation is currently considered as a top priority. This is justified by the course taken by the Government of the Russian Federation to strengthen the social parameters of the economy and improve the standard of living and quality of life of the population. Transport contributes to the organization of the economic space, ensuring the spatial division of labor and the continuity of reproduction processes, as well as the possibility of obtaining the effects of the interconnection of related sectors of the economy. In these conditions, the issues of transport mobility, transport accessibility and transport provision in the regions of Russia are becoming one of the most active in terms of regulation and management. In the context of spatial development, the key factor is an effectively functioning transport infrastructure, which determines, among other things, the quality of life of the population of the region. The

\footnotetext{
* Corresponding author: pantinata@gumrf.ru
} 
formation of transport infrastructure leads to the development of regions, promotes the provision of high-quality transport services in order to increase the connectivity of the economic space and the accessibility of regional resources, which ensures the growth of business activity and the improvement of economic indicators of the regions. However, on the vast territory of the Russian Federation, the placement of transport infrastructure objects is uneven. This affects the indicators of transport accessibility, the values of which differ significantly by type of transport and in different regions. Knowledge of the level, dynamics and growth factors of transport accessibility will allow for effective management of both transport infrastructure facilities and the entire regional transport complex.

\section{Methods and Materials}

In the coming years, the sustainable and balanced development of the Russian economy is associated with the spatial development of the country's economy, which is aimed at reducing interregional differences at the level and quality of life of the population, accelerating economic growth and technological development, as well as ensuring the national security of the country ${ }^{1}$. This strategy involves solving the problem of eliminating infrastructure constraints, improving the accessibility and quality of the main transport, energy, information and telecommunications infrastructure.

A review of scientific publications on the subject of the study showed that at present, the issues of spatial development of territories are relevant in the scientific community. They are represented by studies focused on various management objects. Thus, the author (Suvorova A.V., 2019) points out the features of spatial development, which include changes in the organization of space and its structural characteristics. They include changes in both the physical boundaries of territories and the complex of deformations in the structure of industries, enterprises of regions, the infrastructure used and management methods. The concept of spatial development was established in Europe, Canada, and later in the United States by the early 70 s of the twentieth century. According to the authors (V. Glazychev, P. Shchedrovitsky, 2004), this term is unnecessarily expanded in content, but refers to a "large space" of a strategic scale: from the scale of a country to the scale of the largest city or county, approximately corresponding to the size of a small administrative district in Russia. This explains the specifics of managing the economic space (regions) in large and small countries, as well as the focus of publications and research on regional development, including the transport component of regional development.

Different interpretations of the term "transport accessibility" and its units, including quantitative parameters (passenger kilometers), price (level of transport rates) and temporal (time for trip). In addition, transport accessibility is interpreted as an indicator of the technical readiness of the system that provides passenger transportation, and as a price parameter that reflects the availability of transportation at the offer price. According to most authors, transport accessibility is one of the generalizing parameters of the functioning and development of the economic system, in particular, the transport infrastructure, as well as the social and economic sphere of the region (Ivanov V. M., 2016; Raquel Velho, 2019; Pantina T., Borodulina S., 2015). The use of this indicator in the management of economic space, on the one hand, complicates the manageability of regional objects, on the other hand, makes it possible to improve the efficiency of their transport systems.

Analysis of domestic (Ivanov V. M., 2016; Bugromenko, V. N., 2010) and foreign publications (Cooper J, Corcoran J. 2018; Brown W., Barr A., Scherer J. et al. 2019; Raquel Velho. 2019); Yuliang Zhang, Wenxiang Li, Haopeng Deng, Ye Li, 2020) showed that the focus is primarily on the issues of assessing transport accessibility for various groups of the population, in particular, for workers - trips to work places, features of provision of transport services in cities for the disabled and people with disabilities, as well as assessment of the 
impact of transport accessibility on health and the environment. The indicators of transport accessibility here are the indicators of the share of the population able to reach the city center (district, school, work) in 30-40 minutes; the daily frequency of public transport; the share of specially equipped vehicles for the disabled; price accessibility. The study (Ford, AC; Barr, SL; Dawson, RJ; James P., 2015) of transport accessibility based on the use of the GIS tool offers a quick accessibility analysis for different types of transport, which can be used to study spatial development by accessibility of individual destinations (for example, places of work) based on testing scenarios for future infrastructure. Accessibility reflects the effort required to overcome the spatial separation of two places, and usually reflects utility, such as trip to work place (Handy, S. L.; Niemeier, D. A., 1997; Allen, W. B.; Liu, D.; Singer, S., 1992). The conditions for ensuring transport accessibility in the city are also described in detail in the work (Koenig, J. G., 1980), the factor of the cost of trip between points is highlighted. The study (Horak, J.; Tesla, J.; Fojtik, D.; Vozenilek, V., 2019) is associated with a multidimensional assessment of the potential accessibility of employers based on a large number of transfers, trip time, at the lack of transport diversity. Scientific papers (Kowalski, M., \& Wiśniewski, S., 2019; Pereira, Rafael H. M., 2018; Nelson, A., Weiss, DJ, 2019) are devoted to the analysis of transport accessibility in the context of the spatial development of economic territories, as well as from the perspective of investing in transport infrastructure. The special perspective of transport accessibility research in the works of Russian scientists and researchers is explained by the huge areas of the Russian Federation, which leaves an imprint on the problems and subject of research. Their scientific works often cover issues related to the location of the transport network, modeling, analysis of the efficiency of the use of transport infrastructure in different regions of the country, and the possibilities of improving transport accessibility through different types of transport. In domestic (Timiryanova V. M., Zimin A. F., Zhilina E. V., 2018; Ivanov M. V., 2016) and a number of foreign industry sources, the concept of transport accessibility includes the following subspecies:

- intraregional accessibility (market accessibility studies, the study of the "center destination" system from the point of view of affordability);

- multimodal accessibility associated with the presence of more than one method of movement (type of transport) in space, expressed in parameters of time, price, distance and quality of service;

- multimodal accessibility associated with the use of different types of transport, with the optimization of time, price and distance taken as a criterion.

A number of studies are based on the well-known model of W. Hansen (Hansen, W. G., 1959), which states that the main product of the transport system is the provision of transport accessibility. The results of the study by A. G. Wilson (Lavrinenko P. A., Romashkina A. A., Stepanov P.S., Chistyakov P. A., 2019) allowed for a more accurate description of potential accessibility based on a mathematical model. Often, studies of the development of regional transport systems are based on standard statistical data, such as the consistence and density of the transport network, the provision of transport infrastructure per 1000 inhabitants of the region or per 100 square kilometers, the complex Engel - Yuzuru Kato coefficient (K):

$$
\mathrm{K}=\mathrm{f}(\mathrm{T}, \mathrm{S}, \mathrm{N})
$$

$\mathrm{T}$ - length of the transport network;

$\mathrm{S}-$ area of the region;

$\mathrm{N}$-population in the region.

Hansen's formula was developed in the concept (Levinson, D. M., \& Wu, H., 2020) of general accessibility for all locations, all modes, all goals, at any time during the project life cycle, it explains the phenomenon of spatial location. Also in the study (Ivanov, M. V., 2016) reported a high level of correlation of total Gross Regional Product (GRP in \%) and the share 
of the total transport routes of the Federal district (road, rail and inland water transport) to the total length of transport routes of Russian Federation, as well as shares of the total length of roads of the Federal district in their total length in general. However, these indicators will not be able to assess the sufficiency of the level of development of the transport system in the region to ensure sustainable spatial development. In addition, they do not take into account the configuration of the transport network for the transportation of passengers in localities, the technical and technological features of the transport infrastructure that provide high-speed transportation parameters, the accessibility of various types of transport - air, water, rail, and road. In addition, the use of a limited number of operational and economic indicators does not allow taking into account either the connectivity of internal territorial and transport processes, or the quality of public services, or the degree of influence of the development of the transport network of the region on its social and economic development.

\section{Results and discussion}

Transport accessibility forms the stability of the economic development of the region, affects the qualitative indicators of spatial development. Estimates of the return on investment in infrastructure should be carried out taking into account the increase in transport accessibility parameters, as one of the efficiency criteria. In this regard, it is an urgent task to develop indicators that reflect transport accessibility in the region both in relation to the volume and return on investment, and allow developing and making management decisions in this sphere. The purpose of the description of the transport accessibility indicator is the possibility of an adequate reflection of the capabilities and results of the functioning of the transport system of the region for the purposes of management, decision-making in the transport sector.

Investments in transport infrastructure involve optimizing the proportions of different types of transport in the regional transport service markets that ensure the connectivity of territories. The transport accessibility indicator is a generalizing parameter that gives an idea of both the results of the region's transport system and the effectiveness of infrastructure investments. The transport systems of the Russian regions are represented by different types of transport: road, inland water, rail, and air. The structure and level of their development in different regions have significant differences.

We have previously proved (Borodulina S., Pantina T., 2020) that the development of inland water transport infrastructure (IWT) directly and indirectly affects the economic performance of the country and provides GDP growth, as well as has a number of significant advantages in comparison with other types of transport. In particular, significant differences between types of transport are observed in parameters of the cost and efficiency of investments in their transport infrastructure. IWT, IWT, in the field of which large investment projects are being implemented, serves as a source of growth in business activity, spatial development, the standard of living of the population in the regions, and affects the reduction of the unemployment rate. Despite the fact that the volume of IWT passenger transportations is relatively small - about 12-13 million people per year, in the regions of the Far North, Siberia and the Far East with a small population density, the share of river transportations is significant, and IWT is often an uncontested type of transport. The dynamics and structure of IWT passenger transportation in Russia is shown in figure 1. 
million passengers, total

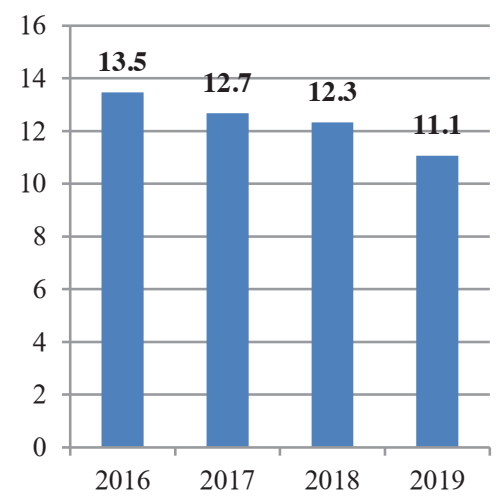

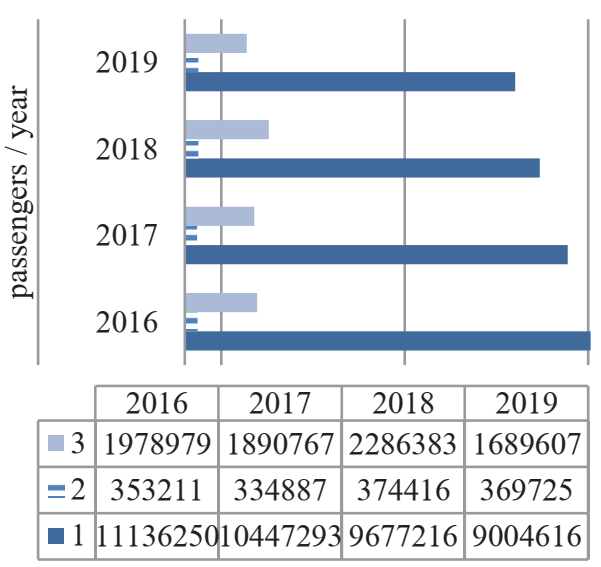

2019

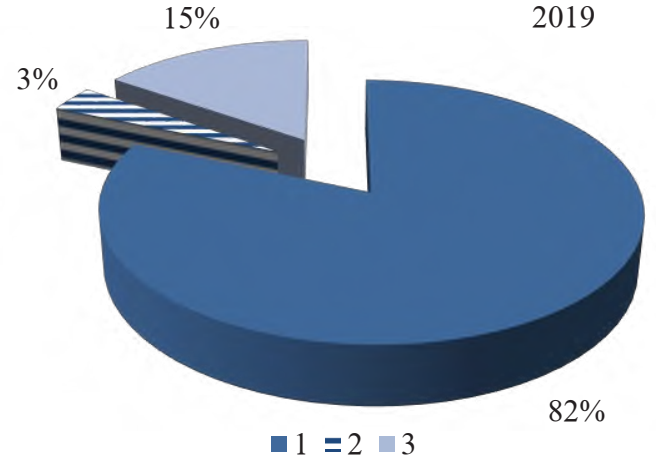

Fig. 1. Dynamics of IWT passenger transportations, as well as its structure, including transportation on transport (1), tourist (2) and sightseeing and walking (3) routes in 2016-2019.

The largest share of IWT passenger transportations is on transport routes $(82 \%)$, which is typical for the entire period from 2016 to 2019. Transport routes include transit, local, suburban, and intra-city passenger transportation routes and ferry crossings. The structure of these transportations with differentiation by regions of Russia in terms of transportation volume (in people) and passenger turnover (in passenger-km), as well as the average distance in $\mathrm{km}$, are shown in figure 2. The federal districts of the Russian Federation are accepted as regions. 

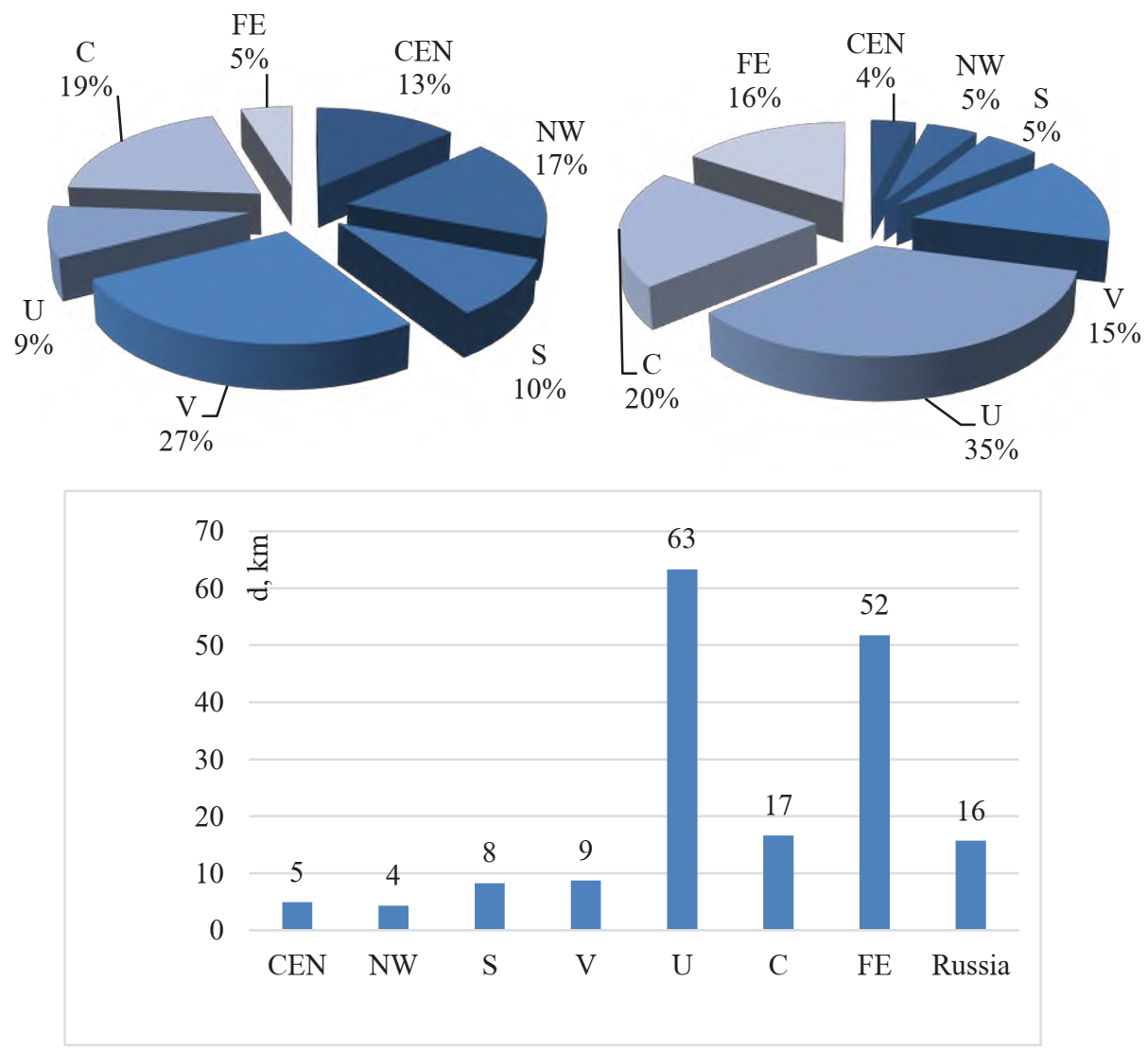

Fig. 2. Structure of passenger transportations on transport routes in 2019 by transportations volume (left) and passenger turnover (center), average distance (right, in kilometers) by regions of the Russian Federation: Central Federal District (CEN), Northwestern (NW), Southern (S), Volga (V), Ural (U), Siberian (C), Far Eastern (FE) Federal districts.

Analysis of the data shows that the indicators reflect the structure and dynamics of passenger transportation IWT by regions have significant differences, which are due to several factors, first of all, geographic location of the region, climatic conditions, infrastructure and other types of transport, economic specialization of the region and the availability of production capacity, population density, etc. The combination of these factors largely determines the demand for IWT services in the passenger transportation segment, taking into account the current model of competition in this region. Based on this message, the authors propose to use the following approach to assessing the transport accessibility of river transportations in the regions of the Russian Federation, which is based on the calculation of the following indicators:

- the share of IWT passenger transportations in the studied $\mathrm{i}$-th (i=1...n) region (Qi) in the total volume of IWT passenger transportations in the Russian Federation (Q):

$$
\mathrm{d}_{\mathrm{Qi}}=\mathrm{Q}_{\mathrm{i}} / \mathrm{Q},
$$

- the coefficient of the average IWT transportation range on transport routes in the i-th region $\left(d_{i 1}\right)$ to the average range of these IWT transportations in the Russian Federation $\left(d_{1}\right)$ :

$$
\mathrm{Kd}_{\mathrm{i}}=\mathrm{d}_{\mathrm{i} 1} / \mathrm{d}_{1},
$$


- the share of passenger transportations on transport routes in the $\mathrm{i}$-th region $\left(\mathrm{Q}_{1 \mathrm{i}}\right)$ to the total volume of IWT passenger transportations in the region (Qi)

$$
\mathrm{d}_{\mathrm{Qi} 1}=\mathrm{Q}_{1 \mathrm{i}} / \mathrm{Q}_{\mathrm{i}}
$$

In this case, the following conditions are met:

- the total IWT passenger transportations volume consists of transportations volumes on transport routes (1), tourist (2) and sightseeing and walking routes (3):

$$
\mathrm{Q}=\mathrm{Q}_{1}+\mathrm{Q}_{2}+\mathrm{Q}_{3},
$$

- the total volume of passenger transportations on transport routes is represented by the sum of traffic volumes on transportations routes in all regions of the Russian Federation:

$$
\mathrm{Q}_{1}=\sum_{\mathrm{i}=1}^{\mathrm{n}} \mathrm{Q}_{1_{\mathrm{i}}},
$$

- the total volume of passenger transportations in the i-th region consists of the volume of transportations on transport routes (1), tourist (2) and sightseeing and walking routes (3):

$$
\mathrm{Q}_{\mathrm{i}}=\mathrm{Q}_{1 \mathrm{i}}+\mathrm{Q}_{2 \mathrm{i}}+\mathrm{Q}_{3 \mathrm{i}} \text {. }
$$

Then the regional transport accessibility index of IWT services in the i-th region $\left(\mathrm{I}^{\mathrm{iwt}}{ }_{\mathrm{i}}\right)$ in the passenger transportations segment will be determined as follows:

$$
\mathrm{I}_{\mathrm{i}}^{\mathrm{iwt}}=\mathrm{d}_{\mathrm{Qi}} \cdot \mathrm{Kd}_{\mathrm{i}} \cdot \mathrm{d}_{\mathrm{Qi} 1}
$$

The table shows the results of calculations for the proposed model for 2019 year. Comparative data on the $\mathrm{I}_{\mathrm{i}}^{\mathrm{iw}}$ indicator for 2016 and 2019 years are shown in figure 3.

Table 1. Results of $\mathrm{I}^{\mathrm{iwt}}{ }_{\mathrm{i}}$ calculations for the federal districts of the Russian Federation for 2019 year.

\begin{tabular}{|c|c|c|c|c|c|c|c|}
\hline Indicator & $\mathbf{V}$ & $\mathbf{C}$ & $\mathbf{C E N}$ & $\mathbf{N W}$ & $\mathbf{S}$ & $\mathbf{U}$ & $\mathbf{F E}$ \\
\hline $\mathrm{Q}_{\mathrm{i}}$ & 2821147 & 2082164 & 1880489 & 1817108 & 1132509 & 783323 & 547208 \\
\hline $\mathrm{Q}$ & 11063948 & 11063948 & 11063948 & 11063948 & 11063948 & 11063948 & 11063948 \\
\hline $\mathrm{Q}_{\mathrm{i} 1}$ & 2410873 & 1715300 & 1203713 & 1570352 & 890590 & 783323 & 430465 \\
\hline $\mathrm{d}_{\mathrm{i}}$ & 8.7 & 16.6 & 4.9 & 4.3 & 8.3 & 63.3 & 51.7 \\
\hline $\mathrm{d}_{1}$ & 15.7 & 15.7 & 15.7 & 15.7 & 15.7 & 15.7 & 15.7 \\
\hline $\mathrm{Kd}_{\mathrm{i}}$ & 0.55 & 1.06 & 0.31 & 0.27 & 0.53 & 4.03 & 3.29 \\
\hline $\mathrm{d}_{\mathrm{Q} i}$ & 0.25 & 0.19 & 0.17 & 0.16 & 0.10 & 0.07 & 0.05 \\
\hline $\mathrm{d}_{\mathrm{Qi1}}$ & 0.85 & 0.82 & 0.64 & 0.86 & 0.79 & 1.00 & 0.79 \\
\hline $\mathrm{I}_{\text {iwt }}$ & 0.12 & 0.16 & 0.03 & 0.04 & 0.04 & 0.29 & 0.13 \\
\hline $\mathrm{I}_{\mathrm{i}}{ }_{\mathrm{i}}(2016)$ & 0.14 & 0.15 & 0.08 & 0.04 & 0.04 & 0.26 & 0.17 \\
\hline
\end{tabular}

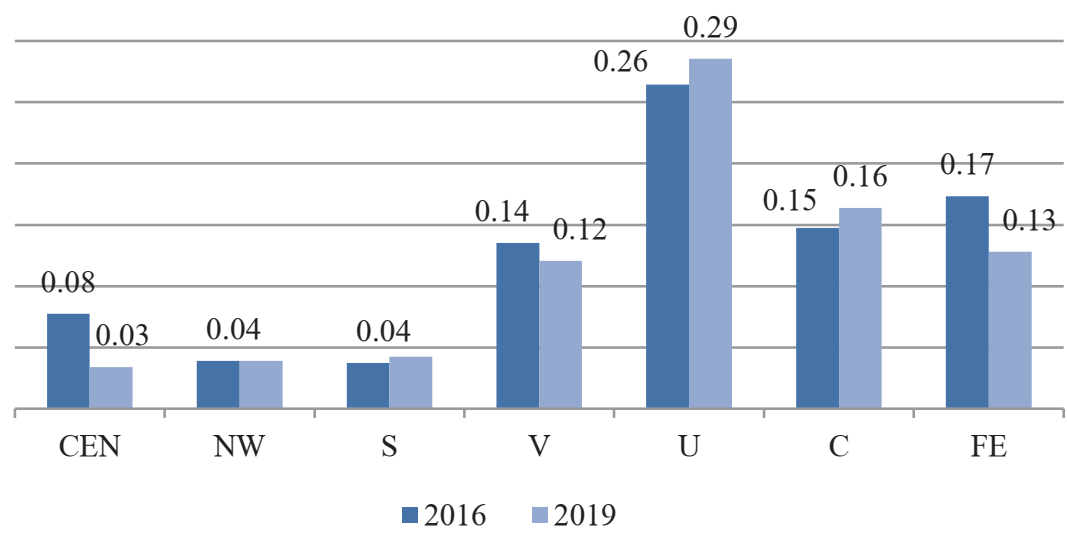

Fig. 3. $\mathrm{I}^{\mathrm{iwt}}{ }_{\mathrm{i}}$ indicator values in 2016 and 2019 years. 
The results of calculations of the regional index of transport accessibility of services of inland water transport in the passenger transportation segment show a wide range of changes in its values by Federal districts of Russia: from 0.03 in Central Federal district to 0.29 in Ural Federal district. In general, the regional index is significantly lower in the regions of the European part of the Russian Federation, which is due to the developed infrastructure of railways and highways with an adequate cost and high quality of transport services offered to passengers by land transport. At the same time, the high value of the index of transport accessibility of inland water transport services in the Ural and Far Eastern Federal districts with relatively small volumes of transportations indicates the high importance of transportations on long-distance transport routes, including on an uncontested basis. The strongest influence on the regional index in the Siberian and Volga Federal districts have a significant volume of passenger transportations (economies of scale), while a larger value of the index at Siberian Federal district is due to high distance of transportations (2 times higher than in the Volga Federal districts).

The assessment of the dynamics of regional transport accessibility indices in conjunction with the analysis of the impact of individual factors on their change in the forecast period during the implementation of IWT infrastructure development projects in the regions of Russia will increase the validity of investment decisions.

\section{Conclusion}

The industry analysis of IWT passenger transportations shows a high degree of heterogeneity of river transportations in the regions of Russia. Improving the organization of the economic space, creating conditions for increasing the demand of the population, ensuring the continuity of passenger transportation processes, developing relevant transport routes and developing transport communications can ensure the growth of transport accessibility and transport provision in the regions of Russia. The model proposed in the paper for assessing the regional index of transport accessibility of IWT services for passenger transportation will help to increase the validity of decision-making related to the functioning and development of the transport infrastructure in the regions.

For further research, the authors set the task of assessing regional transport accessibility indices for road, rail, and air transport services, which will contribute to a deeper understanding of the role and directions of development of the regional transport system, the use of an integrated approach to the placement of transport infrastructure facilities, and the optimization of the distribution of funds from both federal and regional budgets.

\section{References}

1. A.V. Suvorova, Journal of new economy 20(3) (2019) DOI: 10.29141/2658-5081-201920-3-4

2. V. Glazycheva, P. Shhedrovickogo, Doklad Centra strategicheskih issledovanij Privolzhskogo federal'nogo okruga http://www.glazychev.ru/projects/2004_prostrazv/2004_docladprostrazv_oglav.htm

3. M.V. Ivanov, Jekonomika i predprinimatel'stvo 12.2(65-2), 418-422 (2015)

4. Raquel Velho, International Journal of Transportation Science and Technology 8(2), 103-115 (2019) https://doi.org/10.1016/j.ijtst.2018.04.005

5. T.A. Pantina, S.A. Borodulina, Review of European Studies 7(9), $83-96$ (2015) DOI: 10.5539 / res.v7n9p83 
6. V.N. Bugromenko, Transport Rossii. Jelektron. Zhurn (2010) http://www.transportrussia.ru/transport-i-obschestvo/chto-stoit-za-smenoyparadigm.html

7. J. Cooper, J. Corcoran, Journey to work in Australia Canberra (Australian Bureau of Statistics, Australia, 2018) https://www.abs.gov.au/ausstats/abs@.nsf/Lookup/by\%20Subject/2071.0.55.001 2016 $\sim$ Main\%20Features Feature\%20Article:\%20Journey\%20to\%20Work\%20in\%20Austr alia 40

8. W. Brown, A. Barr, J. Scherer et al., Int J Behav Nutr Phys Act 16, 89 (2019) https://doi.org/10.1186/s12966-019-0853-y

9. Yuliang Zhang, Wenxiang Li, Haopeng Deng, Ye Li, Journal of Advanced Transportation 2020, 7645153 (2020) https://doi.org/10.1155/2020/7645153

10. A.C. Ford, S.L. Barr, R.J. Dawson, P. James, ISPRS Int. J. Geo-Inf. 4, 124-149 (2015) https://doi.org/10.3390/ijgi4010124

11. S.L. Handy, D.A. Niemeier, Environ. Plan. A 29, 1175-1194 (1997) https://doi.org/10.1068/a291175

12. W.B. Allen, D. Liu, S. Singer, Transp. Res. B 27, 439-449 (1992) https://doi.org/10.1016/0191-2615(93)90016-4

13. J.G. Koenig, Transportation 9, 145-172 (1980) https://doi.org/10.1007/BF00167128

14. J. Horak, J. Tesla, D. Fojtik, V. Vozenilek, Sustainability 11, 7098 (2019) doi:10.3390/su11247098

15. M. Kowalski, S. Wiśniewski, European Spatial Research and Policy 26(2), 151-176 (2019) https://doi.org/10.18778/1231-1952.26.2.08

16. R.H.M. Pereira, Journal of Transport Geography https://ssrn.com/abstract $=3147748$ or http://dx.doi.org/10.2139/ssrn.3147748

17. A. Nelson, D.J. Weiss, J. van Etten, et al., Nauchnye dannye 6, 266 (2019) https://doi.org/10.1038/s41597-019-0265-5

18. V.M. Timir'janova, A.F. Zimin, E.V. Zhilina, Jekonomika regiona 14(1), 164-175 (2018) DOI: $10.17059 / 2018-1-13$

19. W.G. Hansen, Journal of the American Institute of Planners 25(2), 73-76 (1959)

20. P.A. Lavrinenko, A.A. Romashkina, P.S. Stepanov, P.A. Chistyakov, Studies on Russian Economic Development 30(6), 692-699 (2019) DOI: 10.1134/S1075700719060091

21. D.M. Levinson, H. Wu, Journal of Transport and Land Use 13(1), 129-158 (2020) https://doi.org/10.5198/jtlu.2020.1660

22. S. Borodulina, T. Pantina, Springer. Cham, 806-819 (2020) DOI: https://doi.org/10.1007/978-3-030-57450-5_68 